\title{
Journal Impact Factors, $h$ Indices, and Citation Analyses in Toxicology
}

\author{
Steven B. Bird, MD
}

University of Massachusetts Medical School, Department of Emergency Medicine, Division of Medical Toxicology

\section{INTRODUCTION}

Academic departments, institutions, and funding sources are increasingly interested in quantifying the academic's productive output and quality of individual researchers. Since Gross and Gross first published a detailed analysis of a single journal's bibliography in 1927 [1], there has been a progressive increase in the scientific methods of journal citation quantification. The most commonly used databases are Journal Citation Reports (JCR) and the Science Citation Index (SCI) [2] produced by the Institute for Scientific Information (ISI). Originally introduced in 1961 as a means for retrieving bibliographic data, the SCI has undergone numerous changes, both in its content and methods, as well as how the information from the database is used.

The recent expansion of biomedical knowledge and increasingly sophisticated scientific techniques has led to a proliferation of biomedical journals. The JCR is an annual publication by the ISI, which reports the impact factor and other bibliometric data for thousands of journals-the JCR cited 6,164 journals in 2006, compared with just 4,625 in 1995 [3]. In a remarkably prescient article published over 70 years ago, Bradford (4) found that a small percentage of journals accounts for a large percentage of what is published and that an even smaller percentage of journals accounts for what is most often cited. That is, there are diminishing returns in trying to comprehensively cover the world's body of literature. Careful selection thus is an effective way to avoid "documentary chaos," a phrase coined by Samuel C. Bradford referring to the angst felt when trying to keep up to date with the information explosion.

The JCR provides quantitative tools for ranking, evaluating, categorizing, and comparing journals within and without scientific fields. The impact factor of a journal is a measure of the frequency with which the average article in a journal has been cited in a particular period. The impact factor is the ratio between citations and recent citable items published by a journal. Thus, the impact factor of a journal is calculated by dividing the number of current-year citations to the total items published in that journal during the previous 2 years. Whether erroneous or not, the impact factor is considered a surrogate for the importance or influence of a journal.

While the impact factor is one way to rank journals, it cannot easily be used to rank or objectively rate an individual. In 2005, J. E. Hirsch proposed the $h$ index as a means of quantifying one's academic productivity [5]. While very simple in principle, the $h$ index is slightly more difficult to define. An individual's $h$ index is the number of manuscripts $(\mathrm{N})$ that have each been cited $\mathrm{N}$ or more times. For example, if an author has 8 manuscripts that have each been cited 8 or more times, that individual's $h$ index is 8 . The $h$ index thus rewards academicians for both the quantity and importance or relevance of their publications (where importance and relevance are proportional to citations).

A large contributor to an individual's $h$ index is the duration of an individual's academic productivity. That is, a more senior author will have had more time to publish as well as more time for the subsequent citation of his or her work. In an effort to level the playing field with regard to the $h$ index, it has been proposed to divide an individual's $h$ index by the number of years out of residency, postdoctoral work, or the number of years a researcher has been publishing, thus yielding the so-called $m$ index [5]. Similar $h$ - and $m$-indices for individual journals can be calculated, and each journal's $h$ index is now listed by the JCR. No published literature has addressed the $m$ indices of journals, but these could be calculated by dividing the $h$ index by the number of years of that journal's publication.

Three other core metrics of scientific journals are the immediacy index, cited half-life, and citing half-life. The immediacy

Keywords: Impact factor, h indices, citation analyses, toxicology

Note: There was no outside funding of any kind used for this study.

Corresponding author: Steven B. Bird, MD, University of Massachusetts Medical School, Department of Emergency Medicine, 55 Lake Avenue North, Worcester, MA 01655.Email: BirdS@ummhc.org 
index is a measure of how quickly the "average" article in a given journal is cited. The immediacy index is calculated by simply dividing the number of citations to articles published in a given year by the number of articles published by that journal in the same year [2]. The immediacy index is best used in conjunction with other journal metrics. The immediacy index can assist in adjusting for journals with large versus small circulations because it represents a number based on a per-article basis. However, journals with frequent publication (e.g., weekly or biweekly) will still have a competitive advantage over less-frequently published journals because an article published early in a given year is more likely to be cited within the same year $[2,6]$.

Cited and citing half-lives are easily confused, but they represent fundamentally different data. The cited half-life of a journal indicates the number of years that account for one-half of all citations to that journal. This number is a gauge of the age of articles from that journal that are cited in a given year. For example, if a journal has a cited half-life of 5.0 years in 2006, that means that one-half of all citations to that journal in 2006 were from 2001 to 2006. The citing half-life of a journal, however, represents the age of articles references by that journal in a given year. Specifically, the citing half-life indicates the number of years that account for $50 \%$ of the citations by articles in that journal. For example, if a journal's citing half-life in 2006 is 5.0 years, it means that one-half of the references in that journal's articles from 2006 are 5 years old. A short citing half-life often represents a rapidly changing or developing scientific field $(2,6)$.

The aim of this study was to identify and analyze the mostfrequently cited journals and articles in the field of medical toxicology, as well as to determine the trend of journal impact factors and $h$ indices from 1999 to 2006. Finally, a discussion of these core measures of productivity and relevance are discussed.

\section{METHODS}

The JCR journal list was searched for category of "toxicology" for the years 1999 and 2006. Twenty-seven of the journals considered most applicable to the practice of medical toxicology were included for further analyses and are identified by an asterisk (*) in Table 1. The journal Environmental Health Sciences, which is not indexed under "toxicology" by the JCR, was included for comparison, yielding 28 journals. For all toxicology journals, the impact factors from 1999 and 2006 along with the $h$ indices were recorded. Additionally, the most cited article from each of the JCR's toxicology journal index since 1966 was determined from ISI Web of Science, as was the total number of articles that have been cited 100 or more times from each journal.

To investigate the correlation between a journal's $h$ index and impact factor, the Spearman's correlation coefficient between a journal's 2006 impact factor and $h$ index was determined. Lastly, to compare the performance of the toxicology journals to other medical and scientific journals, the 1999 and 2006 impact factors of 9 selected major journals that occasionally publish articles relevant to toxicology were determined.

\section{RESULTS}

In 1999 a total of 74 journals were listed in the "toxicology" category of JCR; in 2006 the number had increased to 76 (Table 1). There were 6 entirely new journals created in the toxicology category between 1999 and 2006, while 10 journals ceased publication. Two journals, Teratology and Journal of Toxicology and Environmental Health, were each split into 3 new journals. The journal Mutagenesis was added to the toxicology category between 1999 and 2006. The journals that either ceased publication or were dropped from the JCR between 1999 and 2006 are listed in Table 2. Seven of the original 74 journals (10\%) changed titles during the 7 years covered. One journal, SAR and QSAR in Environmental Research, did not have an impact factor calculated by JCR in 1999. Because it is a new journal and just recently indexed by Medline, the Journal of Medical Toxicology is not yet listed in the JCR.

The 27 journals deemed most relevant to clinical toxicology had a mean impact factor of 1.54 in 1999 . By 2006, the mean had increased to 2.01. Adding data from Environmental Health Perspectives to this category resulted in increases in the impact factors for 1999 and 2006 to 1.58 and 2.14, respectively. The entire JCR toxicology category had a mean impact factor of 1.69 and 2.24 in 1999 and 2006, respectively. If the journal Annual Review of Pharmacology and Toxicology, which publishes only review articles, is removed from the above calculation, then the impact factors of the toxicology category decreased to 1.39 in 1999 and 1.99 in 2006.

The most-frequently cited articles from each of the JCR toxicology category journals from 1965 until the end of 2007 are presented in Table 3. The total number of articles from each of the journals that has been cited 100 or more times and 1000 or more times are also provided in Table 3 . A total of 12 articles from all of the journals have been cited more than 1000 times; 9 (75\%) of these articles were published in Annual Review of Pharmacology and Toxicology. From the toxicology category, a total of 1768 articles have been cited more than 100 times; 298 (16.8\%) of these were published in Annual Review of Pharmacology and Toxicology.

The $2006 h$ index of all JCR toxicology journals are presented in Table 1. Because the $h$ index is a new measure and little has been published regarding its application to individual journals, the correlation between $h$ index and the 2006 impact factor for all JCR toxicology journals was determined (Figure 1). The $\mathrm{R}^{2}$ value of 0.6015 demonstrates that there is moderate to large correlation between a toxicology journal's 2006 impact factor and $h$ index.

Table 4 shows the impact factors of 9 selected well-known journals that occasionally publish articles relevant to medical toxicology. For these 9 journals, there was an increase in impact factor from 1999 to 2006 in 7 of 9 (77\%), with mean impact factors of 18.57 in 1999 and 24.94 in 2006 . The overall $h$ indices of these journals are impossible to calculate because they publish so many articles (the JCR can only analyze 10,000 articles at a time) and the $h$ indices are so large. For example, the $h$ index for Nature in the year 2006 alone was greater than 300 . 
Table 1: Bibliometric Data for JCR Toxicology Category Journals

\begin{tabular}{|c|c|c|c|c|c|c|c|}
\hline Journal Name & $\begin{array}{c}\text { Name } \\
\text { changed } \\
\text { from }\end{array}$ & $\begin{array}{c}1999 \\
\text { Impact } \\
\text { factor }\end{array}$ & $\begin{array}{c}2006 \\
\text { Impact } \\
\text { factor }\end{array}$ & $\begin{array}{c}h \\
\text { index }\end{array}$ & $\begin{array}{l}\text { Immediacy } \\
\text { index }\end{array}$ & $\begin{array}{c}\text { Cited } \\
\text { half-life }\end{array}$ & $\begin{array}{c}\text { Citing } \\
\text { half-life }\end{array}$ \\
\hline Annals of Occupational Hygiene & & 1.577 & 1.919 & 45 & 0.808 & 6.6 & 7.4 \\
\hline Annual Review of Pharmacology & & 21.175 & 22.808 & 54 & 7.059 & 6.5 & 5.6 \\
\hline Archiv Fur Lebensmittelhygiene & & 0.355 & 0.131 & 20 & 0.156 & $>10.0$ & 6.9 \\
\hline Archives of Toxicology* & & 1.683 & 1.787 & 70 & 0.336 & 9.1 & 8.2 \\
\hline Bullletin of Environmental Contamination and Toxicology & & 0.617 & 0.505 & 63 & 0.056 & 9.9 & 9 \\
\hline Basic Clinical Pharmacology Toxicology* & $\begin{array}{l}\text { Pharmacology and } \\
\text { Toxicology }\end{array}$ & 1.263 & 1.788 & 14 & 0.277 & 2.2 & 7.4 \\
\hline Birth Defects Research Part B & & new & 1.629 & 10 & 0.312 & 2.7 & 8.6 \\
\hline Cell Biology and Toxicology & & 1.300 & 1.400 & 35 & 0.233 & 6.7 & 8.1 \\
\hline Chemical Research in Toxicology* & & 3.470 & 3.162 & 97 & 0.663 & 6.2 & 7.7 \\
\hline Chemical Speciation and Bioavailability & & 0.533 & 0.879 & 16 & 0 & 7 & $>10$ \\
\hline Chemico Biological Interactions* & & 1.887 & 1.800 & 93 & 0.489 & 7.2 & 7.9 \\
\hline Clinical Toxicology* & $\begin{array}{l}\text { J Toxicology - Clinical } \\
\text { Toxicology }\end{array}$ & 1.732 & 1.091 & 42 & 0.114 & $>10.0$ & $>10.0$ \\
\hline Comparative Biochemistry and Physiology C & & 0.655 & 1.991 & 35 & 0.529 & 8 & 8.4 \\
\hline Critical Reviews in Toxicology* & & 4.906 & 3.707 & 66 & 0.88 & $>10.0$ & 9.9 \\
\hline Drugs & & 4.150 & 4.472 & 128 & 0.464 & 6.6 & 4.6 \\
\hline Ecotoxicology & & 1.377 & 1.400 & 31 & 0.167 & 5.3 & 8.8 \\
\hline Ecotoxicology and Environmental Safety & & 1.276 & 2.000 & 53 & 0.325 & 6.7 & 9.3 \\
\hline Environmental and Molecular Mutagenesis & & 1.990 & 2.653 & 55 & 0.274 & 7.2 & 8 \\
\hline Environmental Toxicology* & & 0.646 & 1.582 & 25 & 0.108 & 5.2 & 8.3 \\
\hline Environmental Toxicology and Chemistry* & & 2.462 & 2.202 & 90 & 0.404 & 6.6 & 7.9 \\
\hline Environmental Toxicology and Pharmacology* & & 0.707 & 1.119 & 26 & 0.179 & 4.1 & 8.4 \\
\hline Experimental and Toxicologic Pathology* & & 0.603 & 0.755 & 24 & 0.152 & 6.5 & 8.7 \\
\hline Fluoride & & 0.469 & 1.611 & 23 & 0.522 & 6.4 & 9.2 \\
\hline Food Additives and Contaminants & & 0.879 & 1.780 & 48 & 0.148 & 5.7 & 7.2 \\
\hline Food and Agricultural Immunology & & 0.794 & 0.667 & 18 & 0.214 & 6.8 & 8.9 \\
\hline Food and Chemical Toxicology & & 1.243 & 2.393 & 71 & 0.3 & 6.6 & 8.5 \\
\hline Human Experimental Toxicology* & & 1.063 & 1.122 & 33 & 0.081 & 7.4 & 8.4 \\
\hline
\end{tabular}


Table 1: (Continued)

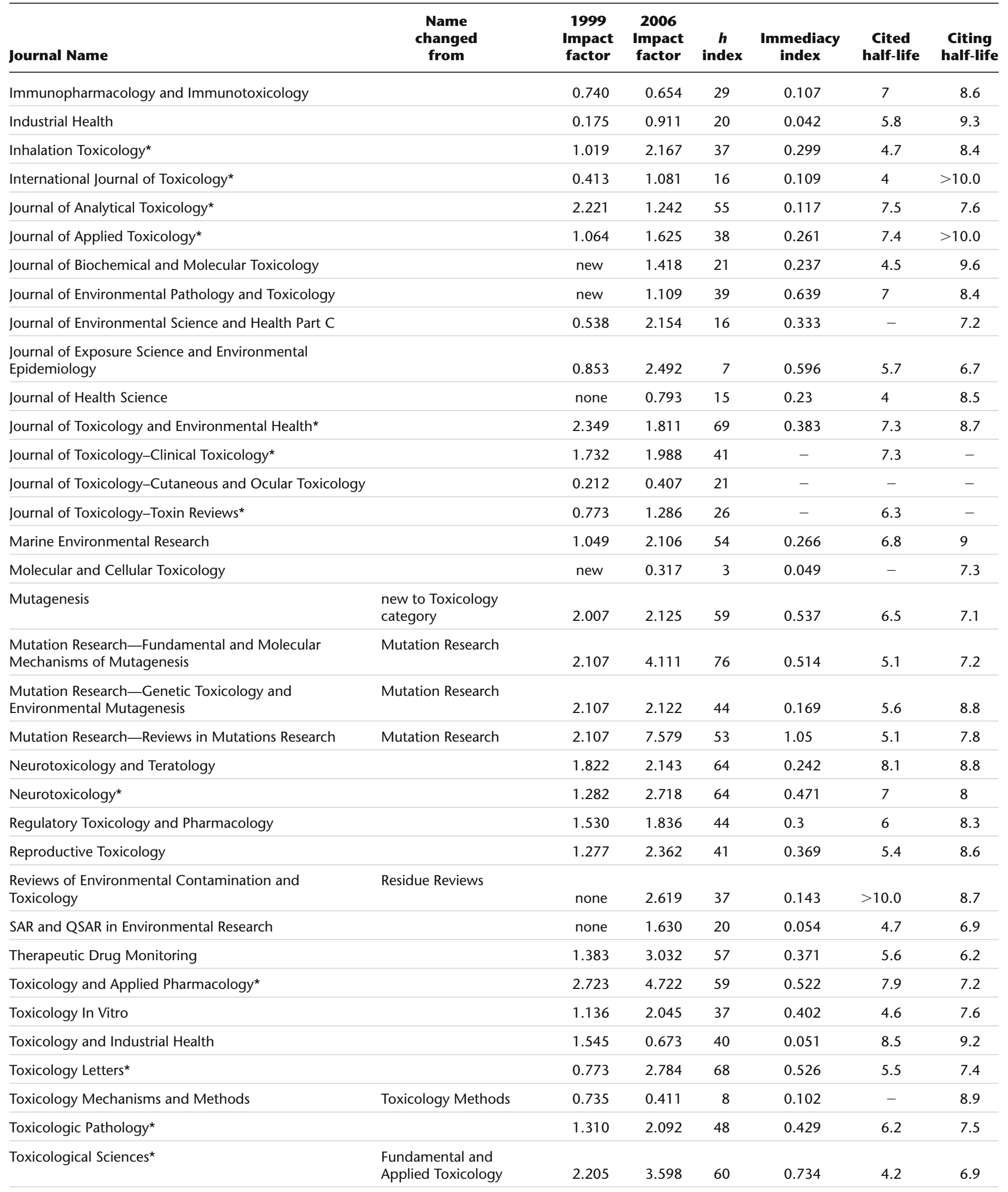


Table 1: (Continued)

\begin{tabular}{|c|c|c|c|c|c|c|c|}
\hline Journal Name & $\begin{array}{c}\text { Name } \\
\text { changed } \\
\text { from }\end{array}$ & $\begin{array}{c}1999 \\
\text { Impact } \\
\text { factor }\end{array}$ & $\begin{array}{c}2006 \\
\text { Impact } \\
\text { factor }\end{array}$ & $\begin{array}{c}h \\
\text { index }\end{array}$ & $\begin{array}{c}\text { Immediacy } \\
\text { index }\end{array}$ & $\begin{array}{c}\text { Cited } \\
\text { half-life }\end{array}$ & $\begin{array}{c}\text { Citing } \\
\text { half-life }\end{array}$ \\
\hline Toxicon* & & 1.248 & 2.509 & 76 & 0.255 & 7.1 & 9.2 \\
\hline Toxin Reviews* & $\begin{array}{l}\text { J Toxicoogy - Toxin } \\
\text { Reviews }\end{array}$ & none & 0.474 & 3 & 0.037 & - & $>100$ \\
\hline Xenobiotica & & 1.335 & 1.613 & 73 & 0.357 & 8.5 & 5.8 \\
\hline
\end{tabular}

Table 2: Journals that Ceased Publication or Were Dropped from JCR between 1999 and 2006

\section{In Vitro and Molecular Toxicology}

In Vitro Toxicology

Journal of Clean Technology Environmental Toxicology and Occupational Medicine

Journal of Natural Toxins

Journal of Pharmacological and Toxicological Methods

Journal of Toxicology and Environmental Health-Part A

Journal of Toxicology and Environmental Health-Part B, Critical Reviews

no longer in $J C R$

Japanese Journal of Toxicology and Environmental Health no longer in JCR

Teratogenesis Carcinogenesis and Mutagenesis

Teratology

Toxic Substances Mechanisms

split into 3 journals

Veterinary and Human Toxicology

\section{DISCUSSION}

There has been a marked proliferation of medical and scientific journals in the last 10 years. However, this proliferation is more significant among disciplines favoring emerging scientific technology than traditional medical specialties or subspecialties. In 1995, there were 72 journals indexed under "toxicology," while in 2005 that category was comprised of 76 journal titles (Table 1). This is in contrast to an increase of $32 \%$ in the number of journals indexed by the ISI Web of Science in the same time period.

Overall, toxicology journals as a group have low impact factors compared to other scientific disciplines. This is likely attributed to several facts. First, the shear numbers of practitioners of medical or clinical toxicology is small, leading to relatively fewer researchers publishing in peer-reviewed journals than other disciplines. Second, while the clinical field of toxicology is small, the subject matter of toxicology is enormous, overlapping with many other scientific and medical specialties. This leads to toxicology manuscripts being published in many other journals that are not classified as "toxicology" by the JCR. Third, the perceived narrow focus of toxicology journals may lead researchers with some connection to toxicology to publish their results in journals that they perceive will have an audience larger than that of toxicology journals. This exact scenario was demonstrated in the emergency medicine literature by Callaham et al. [7]. They found that publications by emergency medicine researchers were cited about 3 times as often when published by non-emergency medicine journals with larger audiences. Fourth, it could be that journals with low impact factors are destined to have low impact factors indefinitely, as researchers seek to publish their results in journals with high impact factors [8].

To quantify both the published productivity and the apparent impact of an individual scientist (as measured by how often that scientist's manuscripts are referenced) as a single metric, J. E. Hirsch in 2005 devised the $h$ index [5]. Sometimes referred to as the Hirsch index or Hirsch number, the $h$ index is simply the number of papers by a scientist that have a citation number $\geq h$. An $h$ index of 20 means, for example, that a scientist has published 20 papers that each had at least 20 citations. In a similar manner, the $h$ index can also be applied to groups of individuals, institutions, and journals. Hirsch's $h$ index was intended to improve upon other measures of productivity, such as the total number of citations or publications, in order to distinguish influential researchers from those who publish many manuscripts that lack influence in their scientific field (again, citations taken as a marker of influence). Because citation conventions differ greatly among different scientific disciplines, the $h$ index should only be used for comparing scientists working in the same field.

As is evident from the calculation of the $h$ index, a scientist's $h$ index can never decrease, and an increase is expected as new (frequently cited) papers are published, as "sleeping beauties" are discovered and cited, and as the scientist's papers attract citations $[9,10]$. The idea of ranking scientists within a given field by a single number and the advantages that the $h$ index has over other 
Table 3: Most Frequently Cited Papers and the Number of Papers Cited 100 or More Times from All JCR Toxicology Journals

\begin{tabular}{|c|c|c|}
\hline Journal and Author & $\begin{array}{c}\# \\
\text { times } \\
\text { cited }\end{array}$ & Most Cited Article \\
\hline \multicolumn{3}{|l|}{ Alcohol } \\
\hline O’Brien CP et al. & 101 & Naltrexone in the treatment of alcoholism: A clinical review. 13:35-39, 1996. \\
\hline \multicolumn{3}{|l|}{ Ann Occup Hyg } \\
\hline Kenny LC et al. & 96 & A collaborative European study of personal inhalable aerosol sampler performance. 41:135-153, 1997. \\
\hline \multicolumn{3}{|l|}{ Ann Rev Pharmacol Toxicol } \\
\hline Watkins JC and Evans RH & 2131 & Excitatory amino-acid transmitters. 21:165-204, 1981. \\
\hline
\end{tabular}

9 articles cited $>1000$ times

298 articles cited $\geq 100$ time

Aquat Toxicol

Jobling $S$ and Sumpter JP

557 Detergent components in sewage effluent are weakly estrogenic to fish—an in-vitro study using rainbow-trout (Oncorhynchus mykiss) hepatocytes.

27:361-372, 1993.

24 articles cited $>100$ times

Arch Environ Contam Toxicol

Kubiak TJ et al.

235 Microcontaminants and reproductive impairment of the Forster's tern on Green Bay, Lake Michigan. 18:706-727,1989.

22 articles cited $>100$ times

Arch Lebensmittelhyg

Arnold D et al.

41 Radioimmunological determination of chloramphenicol residues in muscles, milk and eggs. 35:131-136 1984 .

Arch Toxicol

Johnson MK

330 Improved assay of neurotoxic esterase for screening organophosphates for delayed neurotoxicity potential. 37:113-115, 1977.

29 articles cited $>100$ times

Basic Clin Pharmacol Toxicol

Safe $S$ et al.

214 2,3,7,8-Tetrachlorodibenzo-para-dioxin (TCDD) and related-compounds as antiestrogenscharacterization and mechanisms of action. 69: 400-409, 1991.

12 articles cited $>100$

Biomarkers

d'Errico A et al.

Genetic metabolic polymorphisms and the risk of cancer: A review of the literature. 1:149-173, 1996.

Birth Defects Res Part $A$

Rasmussen SA et al.

Guidelines for case classification for the national birth defects prevention study. 67:193-201, 2003.

Birth Defects Res Part B

Cappon GD et al. administered to rats and rabbits during the sensitive periods for heart development and midline closure. 68:47-56, 2003.

Bull Environ Contam Toxicol

Payne JF and Penrose WR

18 articles cited $>100$ times

Cell Biol Toxicol

Bondessoon I et al.

128 MEIC - a new international multicenter project to evaluate the relevance to human toxicity of in vitro cytotoxicity tests. 5:331-347, 1989.

2 articles cited $>100$ times 
Table 3: (Continued)

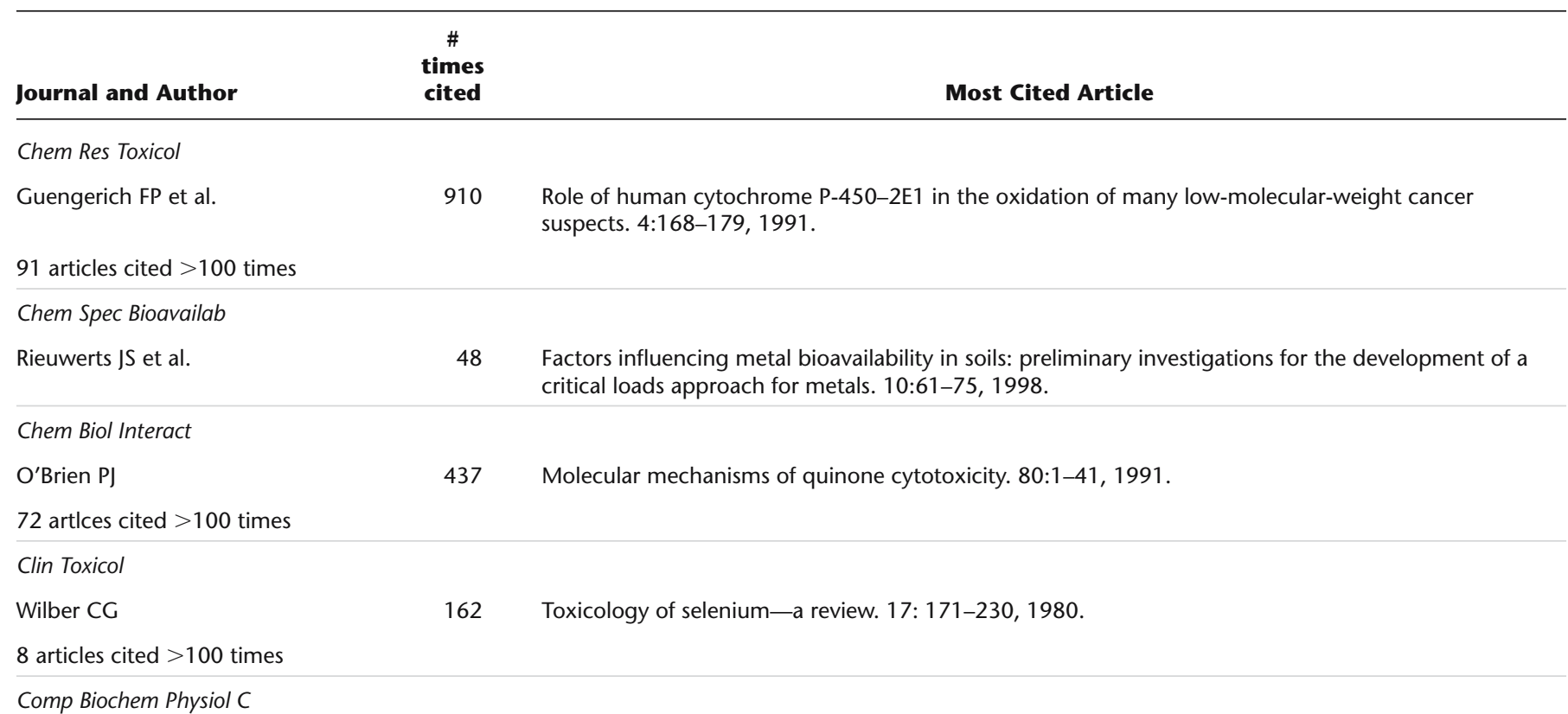

Hahn ME

160 The aryl hydrocarbon receptor: A comparative perspective. 121:23-53, 1998.

2 articles cited $>100$ times

Crit Rev Toxicol

Safe $S$

Polychlorinated-biphenyls (PCBS), dibenzo-para-dioxins (PCDDS), dibenzofurans (PCDF) and related compounds-environmental and mechanistic considerations which support the development of toxic equivalency factors (TEFS). 21:51-88, 1990.

41 articles cited $>100$ times

\section{Cutan Ocul Toxicol}

Farage $\mathrm{M}$ et al.

Cutaneous and sensory effects of two sanitary pads with distinct surface materials: A randomized prospective trial. 24:227-241, 2005.

\section{DNA Repair}

Fernandez-Capetillo O et al.

118 H2AX: the histone guardian of the genome. 3:959-967, 2004.

3 articles cited $>100$ times

Drug Chem Toxicol

Miller RR et al.

79

Chronic toxicity and oncogenicity bioassay of inhaled ethyl acrylate in Fischer 344 rats and B6C3F1 mice. 8:1-42, 1985.

Drug Safety

Vial T and Descotes J

Clinical toxicity of the interferons. 10:115-150, 1994.

9 articles cited $>100$ times

Drugs

Ward A and Clissold SP

Pentoxifylline-a review of its pharmacodynamic and pharmacokinetic properties, and its therapeutic efficacy. 34:50-97, 1987.

212 articles cited $>100$ times

Ecotoxicol Environ Safety

Vanstraalen NM and Denneman CAJ

8 articles cited $>100$ times 


\section{Table 3: (Continued)}

\begin{tabular}{|c|c|c|}
\hline Journal and Author & $\begin{array}{c}\# \\
\text { times } \\
\text { cited }\end{array}$ & Most Cited Article \\
\hline
\end{tabular}

Ecotoxicology

MacDonald DD et al.

114 Development and evaluation of sediment quality guidelines for Florida coastal waters. 5:253-278, 1996.

2 articles cited $>100$ times

Environ Mol Mutagen

Tice RR et al.

649 Single cell gel/comet assay: Guidelines for in vitro and in vivo genetic toxicology testing. 35:206-221, 2000.

17 articles cited $>100$ times

Environ Health Perspect

Colborn T et al.

Developmental effects of endocrine-disrupting chemicals in wildlife and humans. 101: 378-384, 1993.

193 articles cited $>100$ times

Environ Toxicol

Falconer IR

An overview of problems caused by toxic blue-green algae (cyanobacteria) in drinking and recreational water. 14:5-12, 1999.

Environ Toxicol Chem

Jobling $S$ et al.

634

Inhibition of testicular growth in rainbow trout (Oncorhynchus mykiss) exposed to estrogenic alkylphenolic chemicals. 15: 194-202, 1996.

73 articles cited $>100$ times

Environ Toxicol Pharmacol

van der Oost $\mathrm{R}$ et al.

Fish bioaccumulation and biomarkers in environmental risk assessment: a review. 13:57-149, 2003.

1 article cited $>100$ times

Exp Toxicol Path

Dargel $\mathrm{R}$

119 Lipid-peroxidation—a common pathogenetic mechanism. 44:169-181, 1992.

1 article cited $>100$ times

Fluoride

Li JX and Cao SR

Recent studies on endemic fluorosis in China. 27:125-128, 1994.

Food Addit Contam

Price KR and Fenwick GR

305 Naturally-occurring estrogens in foods—a review. 2:73-106, 1985.

5 articles cited $>100$ times

Food Agric Immunol

Nakajima $\mathrm{M}$ et al.

45 Survey of aflatoxin B-1 and ochratoxin A in commercial green coffee beans by high-performance liquid chromatography linked with immunoaffinity chromatography. 9:77-83, 1997.

Food Chem Toxicol

Formica JV and Regelson W

411 Review of the biology of quercetin and related bioflavonoids 33:1061-1080, 1995.

31 articles cited $>100$ times

Human Exp Toxicol

Ashby J et al.

Mechanistically-based human hazard assessment of peroxisome proliferator-induced hepatocarcinogenesis. 13:S1-117, 1994.

2 articles cited $>100$ times

Immunopharm Immunotox

Marzio R et al.

77 CD69 and regulation of the immune function. 21:565-582, 1999. 


\section{Table 3: (Continued)}

\begin{tabular}{|c|c|c|}
\hline Journal and Author & $\begin{array}{c}\# \\
\text { times } \\
\text { cited }\end{array}$ & Most Cited Article \\
\hline
\end{tabular}

Ind Health

Kawakami $\mathrm{N}$ and Haratani $\mathrm{T}$

54 Epidemiology of job stress and health in Japan: Review of current evidence and future direction. 37:174-186, 1999.

Inhal Toxicol

Pope CA and Dockery DW

311 Review of epidemiological evidence of health-effects of particulate air pollution. 7:1-18, 1995.

5 articles cited $>100$ times

Int J Toxicol

Calabrese EJ and Baldwin LA

80 The dose determines the stimulation (and poison): Development of a chemical hormesis database. 16:545-559, 1997.

J Anal Toxicol

Patrianokos $C$ et al.

198 Chemical studies on tobacco smoke: Analysis of aromatic-amines in cigarette smoke. 3:150-154, 1979.

8 articles cited $>100$ times

J Appl Toxicol

Heinrich $U$ et al.

144 Chronic effects on the respiratory tract of hamsters, mice and rats after long-term inhalation of high concentrations of filtered and unfiltered diesel-engine emissions. 6:383-395, 1986.

4 articles cited $>100$ times

J Biochem Mol Toxicol

Maritim AC et al.

Diabetes, oxidative stress, and antioxidants: A review. 17:24-38, 2003.

J Environ Pathol Toxicol

Calleman $\mathrm{C}$ et al.

177 Monitoring and risk assessment by means of alkyl groups in hemoglobin in persons occupationally exposed to ethylene oxide. 2:427-442, 1978.

5 articles cited $>100$ times

J Environ Sci Health C

Chan PC and Huff J

46

Arsenic carcinogenesis in animals and in humans: Mechanistic, experimental, and epidemiological evidence. 15:83-122, 1997.

J Expo Sci Environ Epidemiol

Ahsan $\mathrm{H}$ et al.

20

Health Effects of Arsenic Longitudinal Study (HEALS): Description of a multidisciplinary epidemiologic investigation. 16:191-205, 2006.

J Health Sci

Nishihara T et al.

Estrogenic activities of 517 chemicals by yeast two-hybrid assay. 46:282-298, 2000.

J Toxicol Environ Health

Dreher KL et al.

Soluble transition metals mediate residual oil fly ash induced acute lung injury. 50:285-305,1997.

30 articles cited $>100$ times

J Toxicol/Clin Toxicol

Barceloux DG

Selenium. 37:145-172, 1999.

J Toxicol Toxin Rev

Gordon D et al.

Functional anatomy of scorpion toxins affecting sodium channels. 17:131-159, 1998.

2 articles cited $>100$ times

Mar Environ Res

Alzieu C

Environmental problems caused by TBT in France-assessment, regulations, prospects. 32:7-17, 1991.

10 articles cited $>100$ times 


\section{Table 3: (Continued)}

\begin{tabular}{|c|c|c|}
\hline Journal and Author & $\begin{array}{c}\text { \# } \\
\text { times } \\
\text { cited }\end{array}$ & Most Cited Article \\
\hline
\end{tabular}

Mol Cell Toxicol

Park KS et al.

4 Eco-toxicogenomics research with fish. 1:17-25, 2005.

Mutagenesis

Neill JP et al.

169 Refinement of a lymphocyte-T cloning assay to quantify the in vivo thioguanine-resistant mutant in humans. 2:87-94, 1987.

14 articles cited $>100$ times

Mutat Res-Fund Mol M

Fenech M

260 The in vitro micronucleus technique. 455:81-95, 2000.

38 articles cited $>100$ times

Mutat Res-Gen Tox En

Phillips DH

133 Polycyclic aromatic hydrocarbons in the diet. 443:139-147, 1999.

3 articles cited $>100$ times

Mutat Res-Rev Mutat

Kasai H

362 Analysis of a form of oxidative DNA damage, 8-hydroxy-2'-deoxyguanosine, as a marker of cellular oxidative stress during carcinogenesis. 387:147-163, 1997.

12 articles cited $>100$ times

Neurotoxicology

Bayer SA et al.

321 Timetables of neurogenesis in the human brain based on experimentally determined patterns in the rat. 14:83-144, 1993.

16 articles cited $>100$ times

Neurotoxicol Teratol

Grandjean $\mathrm{P}$ et al.

383 Cognitive deficit in 7-year-old children with prenatal exposure to methylmercury. 19:417-428, 1997.

23 articles cited $>100$ times

Regul Toxicol Pharmacol

Barnes DG and Dourson M

241 Reference dose (RFD)—description and use in health risk assessments. 8: 471-486, 1988.

9 articles cited $>100$ times

Reprod Toxicol

Jansen HT et al.

169 Estrogenic and antiestrogenic actions of $\mathrm{PCBs}$ in the female rat-in vitro and in vivo studies. 7: 237-248, 1993.

4 articles cited $>100$ times

SAR QSAR Environ Res

Greene $\mathrm{N}$ et al.

Knowledge-based expert systems for toxicity and metabolism prediction: DEREK, StAR and METEOR. 10: 299-314, 1999.

Ther Drug Monit

Erling $\mathrm{M}$ et al.

201 Fluvoxamine inhibition and carbamazepine induction of the metabolism of clozapine-evidence from a therapeutic drug-monitoring service. 16: 368-374, 1994.

15 articles cited $>100$ times

Toxicol Appl Pharmacol

Kociba RJ et al.

Results of a 2-year chronic toxicity and oncogenicity study of 2,3,7,8-tetrachlorodibenzo-para-dioxin in rats. 46: 279-303, 1978.

243 articles cited $>100$ times 


\section{Table 3: (Continued)}

\begin{tabular}{|c|c|c|}
\hline Journal and Author & $\begin{array}{l}\text { \# } \\
\text { times } \\
\text { cited }\end{array}$ & Most Cited Article \\
\hline \multicolumn{3}{|l|}{ Toxicol In Vitro } \\
\hline Borenfreund E et al. & 198 & $\begin{array}{l}\text { Comparisons of } 2 \text { in vitro cytotoxicity assays_the neutral red (NR) and tetrazolium MTT tests. 2:1-6, } \\
1988 .\end{array}$ \\
\hline \multicolumn{3}{|l|}{3 articles cited $>100$ times } \\
\hline \multicolumn{3}{|l|}{ Toxicol Ind Health } \\
\hline Vom Saal FS et al. & 275 & $\begin{array}{l}\text { A physiologically based approach to the study of bisphenol A and other estrogenic chemicals on the } \\
\text { size of reproductive organs, daily sperm production, and behavior. 14: } 239-260,1998 \text {. }\end{array}$ \\
\hline \multicolumn{3}{|l|}{6 articles cited $>100$ times } \\
\hline \multicolumn{3}{|l|}{ Toxicol Lett } \\
\hline \multicolumn{3}{|l|}{24 articles cited $>100$ times } \\
\hline \multicolumn{3}{|l|}{ Toxicol Mech Methods } \\
\hline Gupta RC & 27 & $\begin{array}{l}\text { Brain regional heterogeneity and toxicological mechanisms of organophosphates and carbamates. } \\
14: 103-143,2004 \text {. }\end{array}$ \\
\hline \multicolumn{3}{|l|}{ Toxicol Pathol } \\
\hline \multicolumn{3}{|l|}{4 articles cited $>100$ times } \\
\hline \multicolumn{3}{|l|}{ Toxicol Sci } \\
\hline \multicolumn{3}{|l|}{23 articles cited $>100$ times } \\
\hline \multicolumn{3}{|l|}{ Toxicol } \\
\hline $\begin{array}{l}\text { Price RG } \\
43 \text { articles cited }>100 \text { times }\end{array}$ & \multicolumn{2}{|c|}{43 articles cited $>100$ times } \\
\hline \multicolumn{3}{|l|}{ Toxicon } \\
\hline \multicolumn{3}{|l|}{32 articles cited $>100$ times } \\
\hline \multicolumn{3}{|l|}{ Toxin Rev } \\
\hline \multicolumn{3}{|l|}{3 articles cited $>100$ times } \\
\hline \multicolumn{3}{|l|}{ Vet Human Toxicol } \\
\hline Bruning-Fann CS and Kaneene JB & 90 & The effects of nitrate, nitrite, and n-nitroso compounds on human health-a review. 35:521-538, 1993. \\
\hline \multicolumn{3}{|l|}{ Xenobiotica } \\
\hline Oesch F & 745 & $\begin{array}{l}\text { Mammalian expoxide hydrases_inducible enzymes catalyzing inactivation of carcinogenic and } \\
\text { cytooxic metabolites derived from aromatic and olefinic compounds. } 3: 305-340,1973 \text {. }\end{array}$ \\
\hline 35 articles cited $>100$ times & & \\
\hline
\end{tabular}

citation-based indices (for example, ranking by total number of papers, total number of citations, or the number of citations per paper) quickly attracted the attention of major scientific journals, including Science and Nature $[11,12]$. The $h$ index is seen to have the advantage that it gives a robust estimate of the broad impact of a scientist's cumulative research contributions $[5,9]$. This means that the $h$ index is insensitive to a set of infrequently or non-cited papers or to one or several highly cited papers: A scientist with very few highly cited papers or, alternatively, many lowly cited papers will have a low $h$ index. A further advantage for the $h$ index is that the necessary data for calculation is easy to access in the Thomson Scientific Web of Science. The $h$ index can 


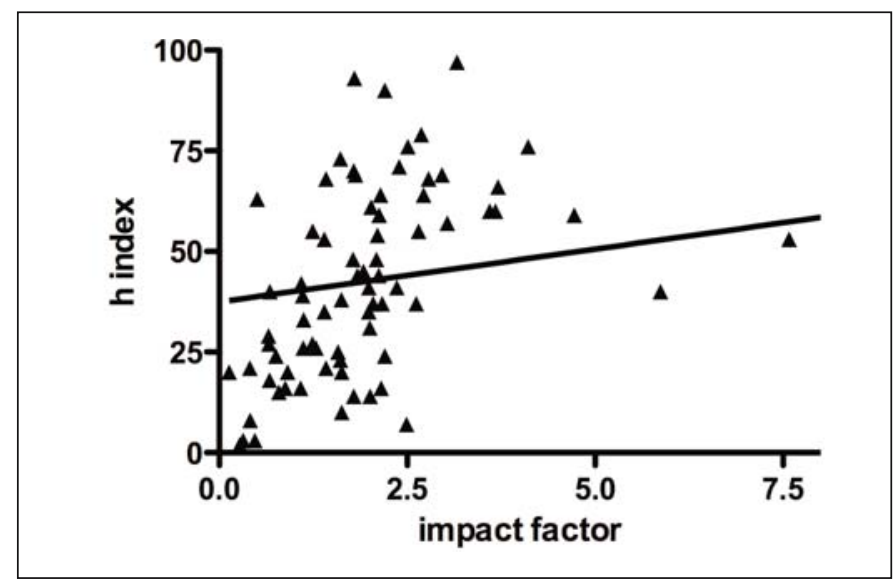

Figure 1: Relationship of $\mathrm{h}$ index to impact factor for JCRR Toxicology journals.

Table 4: 1999 and 2006 Impact Factors for Selected Highly Cited Journals

\begin{tabular}{lcr}
\hline Journal & $\begin{array}{c}\mathbf{1 9 9 9} \\
\text { Impact } \\
\text { Factor }\end{array}$ & $\begin{array}{c}\mathbf{2 0 0 6} \\
\text { Impact } \\
\text { Factor }\end{array}$ \\
\hline Nature & 29.49 & 26.68 \\
\hline New England Journal of Medicine & 28.86 & 51.30 \\
\hline Nature Medicine & 26.58 & 28.59 \\
\hline Science & 24.59 & 30.03 \\
\hline Journal of Experimental Medicine & 15.65 & 14.48 \\
\hline JAMA & 11.43 & 23.18 \\
\hline Proceedings of the National Academy of Sciences & 10.26 & 9.64 \\
\hline Lancet & 10.20 & 25.80 \\
\hline Annals of Internal Medicine & 10.10 & 14.78 \\
\hline
\end{tabular}

be viewed by first searching the ISI Web of Knowledge database by author, then using the "Create Citation Report" option. Both graphical and numerical representations of that author's cumulative citations, numbers of citations per year, as well as the $h$ index are then provided.

Even though the $h$ index was rapidly adopted by academia [13] and the $J C R$, it remains an incomplete marker of academic success for several reasons. Perhaps most important, the $h$ index is biased against junior investigators [14]. This is because more senior authors have both a longer time span of publications as well as a greater number of publications compared to junior authors-thus Hirsch devised the $m$ index [5]. An $m$ index of $\geq 1$ is considered a successful research career, whereas an $m$ index of $\geq 3$ represents a truly extraordinary researcher uncommon at even the highest academic centers. The $m$ index has attracted limited attention so far, but with the advent of more methods to level the academic-promotion playing field, it is likely that the $m$ index and additional metrics will be promulgated.

Because an author's $h$ index can never decline, it is also biased in favor of more senior researchers, as their apparent scientific impact in a field of study will continue even beyond their academically productive time. Moreover, the $h$ index currently considers primary authorship, senior authorship, and coauthorship to be equal. Therefore, an individual with frequent coauthorship on highly cited papers, but with few on no primary author papers, will have a high $h$ index while their scientific contributions may be quite modest. Ironically, an individual's $h$ index can also be elevated by frequent citations to work that has been refuted, questioned, or found to be entirely wrong.

The $h$ index can also be applied to journals, and is viewed as a metric of a journal's influence. In fact, the JCR now provides $h$ index information on all of its indexed journals. In order to increase the impact factor and $h$ index, journals can adopt editorial policies that improve the likelihood of citations to its articles. One method to do this is to publish a large percentage of review articles, which are sources of frequent citation. It has been stated that up to $90 \%$ of published scientific articles are never cited [15] and that more than one-half of research articles remain uncited after 3 years [16]. However, nearly all review articles receive at least 1 citation. This has led some authors to question the applicability of calculating an impact factor for review articles [13]. Another editorial policy to increase citations to a journal is the application of editorial pressure to authors: that is, some editors request authors to cite work published in that journal, whether by other authors or by self-citation [13]. Regardless of the method applied, editorial practices aimed solely to increase a journal's subsequent citations and reputation cannot be condoned.

However, a journal's reputation may not tell the complete story about its impact on the scientific and scholarly communities. In fact, Christenson and Sigelman found the opposite to be true [17]. They found a nonlinear relationship between a journal's reputation and its impact, especially at the extremes of the "prestige" scale. They concluded that citation data "permit scholars to evaluate the importance of journals based not on opinion but on the frequency of citations" and that "frequency of citation implies scholarly acceptance ...." As further evidence of the importance of a journal's reputation, Callaham et al. found that the impact factor of the journal was more important than any other variable in determining the subsequent citation frequency of an article [18].

As discussed briefly, a journal's total circulation number can also affect its impact factor and $h$ index. That is, the more individuals and institutions subscribe to a given journal, the larger its readership and potential audience. This fact places smaller journals at a competitive disadvantage relative to larger journals or journals that publish more issues per year. In an attempt to control for a journal's circulation, Barendse investigated what was termed the strike rate index (SRI) [19]. The SRI is based on the log relationship of the $h$ index and the size of the journal. Barendse found that there is a linear log-log relationship between the 
$h$ index and the size of the journal [19]. That is, the larger the journal, the more likely it is to have a high $h$ index. When he looked at journals from 4 scientific disciplines, he found a similar distribution of the SRI, perhaps allowing journals across diverse fields to be compared to each other.

There are also some fundamental limitations to the JCR. For instance, the assignment of a journal to one or more categories may not reflect fully that journal's entire audience. As an example, Environmental Health Perspectives-a well-regarded journal that frequently publishes articles of interest to toxicologists-is listed in the JCR categories of "environmental sciences" and "public, environmental, and occupational health" while it is absent from "toxicology." Thus, the accuracy or appropriateness of journal categories is dependent on the appropriate indexing of journals. As with any indexing, there is also a delay in the categorization of a journal. For instance, the Journal of Medical Toxicology is not yet indexed by the JCR. The JCR is also heavily biased towards journals published in the United States, Canada, and United Kingdom. This introduces bias against researchers not from these countries and excludes highly cited works published in many foreign journals [20]. Another important limitation to the JCR is that both impact factors and $h$ indices of commentaries, editorials, perspectives, news articles, and other nonoriginal research are also calculated and included for each journal. These types of short, time-sensitive articles (a staple of journals that publish weekly editions) are often highly cited and contribute to a journal's citation analysis [21].

Considering that $10 \%$ of toxicology journals changed names from 1999 to 2006, a brief discussion of how the Journal Citation Reports handles these changes (and how the changes affect the impact factor) is warranted. This is best demonstrated by an example. Assume that in 2007 "Journal A" publishes its last issue, and that in 2008 the first issue is newly titled "Journal B." When the 2007 JCR is published (in June of 2008), only Journal $A$ will be listed-because there were neither articles nor citations to Journal $B$ in the year before its release. The listing for Journal $A$ will have all of the JCR metrics.

When the 2008 JCR is published (in June of 2009), Journal A will have a listing based upon citation in 2008 to content published in 2006 and 2007. Journal B will have a deceptively low impact factor based on citations in 2008 to articles published in 2008. For the 2009 JCR (published in June of 2010), Journal A will have data listed based on citations in 2009 to articles published only in 2007. Journal B will have data based on citations in 2009 to articles published in 2008 only. Thus, the impact factor of Journal $A$ in 2009 would be deceptively high, since it is based on a section of the citation time-course that is higher (that is, the greatest number of citations occur in the second year after publication). The impact factor of Journal B, on the other hand, would be somewhat lower than expected, since it is based on citations only to very recent articles. To gauge the performance of the journal across the time of the title transition, one simply adds the 2 individual impact factors. Finally, in data for the year 2010published in June of 2011—only Journal B will be listed.

\section{CONCLUSION}

Overall, toxicology journals have low impact factors compared to other scientific journals. As academic promotion boards increasingly use semiquantitative methods of determining academic productivity (such as the impact factor and $h$ index of the journals in which a person has published), it could be expected that the toxicology journals in which many people in the fields of medical and clinical toxicology publish will see decreased submissions, as authors attempt to get their work published in journals with higher impact factors.

The authors have no potential financial conflicts of interest to report.

\section{REFERENCES}

1. Gross PLK, Gross EM. College libraries and chemical education. Science 1927;66:385.

2. Information IfS. 2006 Science Citation Index. Journal Citation Reports. Philadelphia: Institute for Scientific Information; 2006.

3. Andersen J, Belmont J, Cho CT. Journal impact factor in the era of expanding literature. J Microbiol Immunol Infect 2006;39:436-43.

4. Bradford SC. Sources of Information on Specific Subjects. Engineering: An Illustrated Weekly Journal 1934;137:85-86.

5 . Hirsch JE. An index to quantify an individual's scientific research output. Proc Natl Acad Sci U S A 2005;102: 16569-16572.

6. Sims JL, McGhee CNJ. Citation analysis and journal impact factors in ophthalmology and vision science journals. Clin Experiment Ophthalmol 2003;31:14-22.

7. Callaham M, Weber E, Wears R. Citation characteristics of research published in Emergency Medicine versus other scientific journals. Ann Emerg Med 2001;38:513-517.

8. Ioannidis JP. Concentration of the most-cited papers in the scientific literature: analysis of journal ecosystems. PLoS ONE 2006;1:e5.

9. Cronin B, Meho L. Using the h-index to rank influential information scientists. Journal of the American Society for Information Science and Technology 2006;27:1275-1278.

10. van Raan AF. Sleeping Beauties in Science. Scientometrics 2004;59:467-472.

11. Bhattacharjee Y. Data Point. Impact Factor. Science 2005;309:1181.

12. Ball P. Index aims for fair ranking of scientists. Nature 2005;436:900.

13. Monastersky R. The Number That's Devouring Science. The Chronicle of Higher Education 2005 October 14.

14. Kelly CD, Jennions MD. H-index: age and sex make it unreliable. Nature 2007;449:403.

15. Meho L. The rise and rise of citation analysis. Physics World 2007;29:32-36. 
16. Redner S. Citation Statistics from 110 Years of Physical Review. Phys Today 2005;58:49-54.

17. Christenson JA, Sigelman L. Accrediting knowledge: Journal stature and citation impact in social science. Soc Sci Q 1985;66:964-975.

18. Callaham M, Wears RL, Weber E. Journal prestige, publication bias, and other characteristics associated with citation of published studies in peer-reviewed journals. JAMA 2002;287: 2847-2850.
19. Barendse W. The strike rate index: a new index for journal quality based on journal size and the h-index of citations. Biomed Digit Libr 2007;4:3.

20. Rey-Rocha J, Martin-Sempere MJ, Martinez-Frias J, LopezVera F. Some misuses of Journal Impact Factor in research evaluation. Cortex 2001;37:595-597.

21. Garfield E. The history and meaning of the journal impact factor. JAMA 2006;295:90-93. 